\title{
Association of the CLC-Kb T481S polymorphism with childhood hypertension
}

\author{
Rainer Büscher
}

University of Duisburg-Essen, Children's Hospital, Pediatrics II, Essen, Germany; rainer.buescher@uk-essen.de

Received 17 March 2010; revised 29 March 2010; accepted 31 March 2010.

\begin{abstract}
Essential hypertension is a difficult diagnosis in children and the gene of the renal-epithelial chloride channel $\mathrm{ClC}-\mathrm{Kb}$ is potentially predisposing. In vitro studies have shown that a common ClC-Kb threonine481serine (T481S) polymorphism leads to enhanced chloride channel activity and may predispose for hypertension (HT). We therefore analysed children at risk for $\mathrm{HT}$ for the T481S polymorphism and associated genotype with blood pressure (BP) status. A total of 48 children with essential hypertension (mean age $14.4 \pm 2.7$ years, 26 male; 22 female; mean BP $143.4 \pm 7.5 / 88 \pm 5.8 \mathrm{mmHg}$ ) were compared with 78 children with white-coat HT (WCHT), who showed occasionally hypertensive BP values, which were not confirmed by ambulatory blood pressure monitoring (mean age $13.7 \pm 2.5$ years, 49 male, 29 female; mean BP $122.4 \pm 4.3 / 68.2 \pm 3.5 \mathrm{mmHg}$ ). Other causes of HT were excluded. Allelic frequencies of hypertensive patients were not significantly different from those with WCHT (HT: A 0.84; T 0.16 vs. WCHT: A 0.85 ; T 0.15). However, the T-allele was observed more frequently in WCHT subjects with systolic and diastolic BP exceeding the $90^{\text {th }}$ percentile (A 0.71; T 0.29, $n=34, p<0.05$, considered as borderline hypertensive). The preliminary data suggest that children with WCHT carry the CIC-Kb T481S polymorphism more often and that this variant may predispose for development of arterial HT.
\end{abstract}

Keywords: Essential Hypertension;

White-Coat Hypertension;

Ambulatory Blood Pressure Monitoring (Abpm);

Clc-Kb T481s Polymorphism;

Renal-Epithelial Chloride Channel

\section{INTRODUCTION}

Essential hypertension in childhood is rare and in most cases, diagnosis can only be confirmed by exclusion of other causes of hypertension (HT) such as renovascular disease, endocrine or cardiovascular disorders [1,2]. In childhood, HT is defined as blood pressure (BP) exceeding the $95^{\text {th }}$ percentile for healthy children and Ambulatory Blood Pressure Monitoring (ABPM) is an important method for the detection and therapeutic monitoring of children and adolescents with HT [3-5]. White Coat Hypertension (WCHT) is the most common diagnosis in children referred for evaluation of HT (> 50\%) but there is doubt whether occasionally occurring hypertensive episodes predispose for end-organ damage as adult patient [6].

There is increasing evidence that disturbances in the renal tubular sodium chloride $(\mathrm{NaCl})$ reabsorption are predisposing for the development of HT. The renalepithelial chloride channel $\mathrm{ClC}-\mathrm{Kb}$ is expressed in the baso-lateral cell membrane of the distal nephron and is involved in $\mathrm{NaCl}$ reabsorption, therefore, the $\mathrm{ClC}-\mathrm{Kb}$ gene might influence development of HT. Recently, a frequent polymorphism has been detected in the $\mathrm{ClC}-\mathrm{Kb}$ gene (threonine to serine amino acid change, T481S) and in vitro data confirmed that the $C l C-K b$ T481S polymorphism leads to enhanced activation of the chloride channel $[7,8]$. Carriers of the ClC-Kb T481S polymorphism might therefore be at risk for elevated BP. However, this hypothesis has not been verified in a cohort of hypertensive adult or paediatric patients so far.

The aim of our study is to genotype children and adolescents at risk for development of essential hypertension for the ClC-Kb T481S polymorphism and associate the presence of the polymorphism with elevated BP.

\section{MATERIALS AND METHODS}

Over the past 15 years ABPM has been performed in more than 3000 children in our department. Among th- 
ose, 126 Caucasian patients, who were seen at least three times in our clinic, were diagnosed as WCHT. ABPM (SpaceLabs 90217 oscillometric device, Redmond, Washington, USA) confirmed hypertensive BP values according to the percentiles of Soergel et al. [3] in only 48 patients, while diagnosis was not confirmed in 78 patients. Organic reasons for HT like renovascular or cardiovascular pathology or endocrine disorders were excluded and extended diagnostic analysis did not reveal other feasible reasons for HT in 48 children. All 126 patients (48 HT, 22 female; 78 WCHT, 29 female) were included in our study and EDTA blood samples or buccal swabs were taken during a routine visit in order to generate genomic DNA. Patients were not significantly different regarding age (HT $14.4 \pm 2.7$ vs. WCHT $13.7 \pm$ 2.5 years), height (HT $153.6 \pm 22.6$ vs. WCHT $151.5 \pm$ $25.7 \mathrm{~cm}$ ), weight (HT $57.1 \pm 20.4 \mathrm{~kg}$ vs. WCHT $56.5 \pm$ $23.9 \mathrm{~kg}$ ) and BMI (HT $23.17 \pm 5.0$ vs. WCHT $23.75 \pm$ $5.4 \mathrm{~kg} / \mathrm{m}^{2}$ ).

Genotyping for the $C l C-K b$ T481S polymorphism was performed using SSCP and direct sequencing as described before $[7,8]$. Results are expressed as mean \pm SEM. Comparison between the distribution of alleles was performed using a $\chi^{2}$-test. A $p<0.05$ was considered statistically significant. The study was approved by the board of ethics of the University of Duisburg-Essen and all patients and their parents gave their written consent.

\section{RESULTS}

A total of 126 patients were diagnosed as WCHT but diagnosis was confirmed by ABPM in only 48 patients. HT and WCHT patients were not different regarding height, weight, and BMI. Systolic and diastolic BP was significantly increased in hypertensive patients (systolic daytime141 $\pm 10 \mathrm{mmHg}$, diastolic daytime $83 \pm 11$ mmHg; systolic nighttime $127 \pm 8$, diastolic nighttime $67 \pm 13 \mathrm{mmHg}$ ) when compared to $78 \mathrm{WCHT}$ patients (systolic daytime $115 \pm 14 \mathrm{mmHg}$, diastolic daytime 71 $\pm 10 \mathrm{mmHg}$; systolic nighttime $105 \pm 14$, diastolic nighttime $60 \pm 8 \mathrm{mmHg}$ ).

A total of 126 patients were genotyped for the presence of the $C l C-K b$ T481S polymorphism (Table 1). Allelic frequencies for the A- and T-allele in hypertensive and WCHT patients were not significantly different between both groups (A-allele: HT 0.84 vs. WCHT 0.85; T-allele: HT 0.16 vs. WCHT 0.15) and did not differ from data obtained from population studies in the literature [8] (Table 1). The distribution of all genotypes was in Hardy-Weinberg equilibrium. When looking more detailed in the group of WCHT patients whose BP exceeds the $90^{\text {th }}$ percentile, we identified 34 out of 78 patients
Table 1. Allele and genotype frequency distribution of ClC-Kb T481S.

\begin{tabular}{|c|c|c|}
\hline Genotype & $\mathrm{HT}(\mathrm{n}=48)$ & WCHT $(\mathrm{n}=78)$ \\
\hline $\begin{array}{l}\text { T481T } \\
\text { (homozygous noncarriers) }\end{array}$ & $6(75 \%)$ & $58(74.4 \%)$ \\
\hline $\begin{array}{l}\text { T481S } \\
\text { (heterozygote carriers) }\end{array}$ & $9(18.8 \%)$ & 17 (21.8\%) \\
\hline $\begin{array}{l}\text { S481S } \\
\text { (homozygous carriers) }\end{array}$ & $3(6.2 \%)$ & $3(3.8 \%)$ \\
\hline \multicolumn{3}{|l|}{ Allele } \\
\hline A-allele & $(\mathrm{n}=81) 0.84$ & $(\mathrm{n}=133) 0.85$ \\
\hline T-allele & $(n=15) 0.16$ & $(n=23) 0.15$ \\
\hline \multicolumn{3}{|c|}{$\begin{array}{l}\text { Allelic frequency of CIC-Kb T481S in WCHTchildren (RR > } \\
\left.90^{\text {th }} \text { percentile, } n=34\right)\end{array}$} \\
\hline A-allele & \multicolumn{2}{|l|}{$(\mathrm{n}=48) 0.71$} \\
\hline T-allele & \multicolumn{2}{|c|}{$(\mathrm{n}=20) 0.29^{*}$ vs. 0.15} \\
\hline
\end{tabular}

${ }^{*} p<0.05$, Fisher exact test and $\chi^{2}$-test

(44\%) fulfilling criteria of a borderline HT. In this subgroup, the allelic frequency was significantly shifted towards the T-allele (A-allele 0.71 vs. T-allele 0.29; $\mathrm{p}<$ 0.05 when compared to 0.15 in all other patients of this group), suggesting that patients at risk for the development of HT express the T-allele more often (Table 1).

\section{DISCUSSION}

Hypertension is a major risk factor for the development of cardiovascular and cerebrovascular complications such as heart attack and stroke [9]. Hypertensive end-organ damage has also been demonstrated in children and there is a huge scientific and economic interest in identifying children and adolescents at risk for developing HT in order to initiate preventive treatment [10]. Therefore, even if HT does not appear to be significant initially, children with borderline HT should have continuing follow-up of their BP and monitoring for the complications of HT. Our preliminary data suggest that children with borderline HT carry the ClC-Kb T481S polymorphism more often. The T481S polymorphism has been described to be the first mutation that leads to a pronounced gain of channel function and might therefore contribute to elevated BP $[7,8]$.

We are aware of the limitations of our retrospective study such as small patients number and single center design. However, this is the first study to support the in vitro findings by Jeck and co-workers $[7,8]$ that the 
ClC-Kb T481S polymorphism detects children at risk for development of HT while few other studies in adult hypertensive patients did not identify a positive correlation so far [11]. Extended analysis and a larger population of children with marginal elevated BP values are required to clearly answer this question.

It is well known that renal tubular $\mathrm{Na}^{+}$and $\mathrm{Cl}^{-}$transport mediate BP control by influencing the extracellular fluid volume [12]. Therefore, genes involved in the regulation of renal salt absorption are of potential interest as candidate genes for the development of renal HT. Jeck et al. [7,8] demonstrated that the $C l C-K b$ gene T481S polymorphism leads to activation of the chloride channel in the kidney. It is therefore feasible to hypothesize that also minor changes in the handling of renal salt absorption might lead to elevated BP. Proof of concept using chloride absorption would be interesting to study. However, due to the retrospective design of this study and the lack of established standards in renal tubular chloride handling in children, we are unable to test this hypothesis in our study population.

It is important to know that all patients investigated are European Caucasians which makes the possibility unlikely that a subpopulation with a different ethnical background exists Therefore, we can speculate that the increased prevalence of the T-allele in patients with borderline HT is feasible and not biased by their genetic background. However, other co-factors predisposing for HT such as obesity or metabolic syndrome cannot be ruled out [13]. In this respect it is interesting to notice that both, hypertensive and WCHT patients had an increased BMI exceeding $23 \mathrm{~kg} / \mathrm{m}^{2}$ making obesity a likely risk factor for development of HT in our study population.

In conclusion, children and adolescents with borderline HT carry the $C l C-K b$ T481S polymorphism more often and this genetic variant might predispose for the development of arterial HT. Larger scale studies in genetically diverse populations excluding other predisposeing factors of HT are needed to prove these observations.

\section{REFERENCES}

[1] Sorof, J.M., Lai, D., Turner, J., Poffenbarger, T. and Portman, R.J. (2004) Overweight, ethnicity, and the prevalence of hypertension in school-aged children. $P e$ diatrics; 113(3), 475-482.

[2] Nguyen, M. and Mitsnefes M. (2007) Evaluation of hypertension by the general pediatrician. Current Opinion in Pediatrics, 19(2), 165-169.

[3] Soergel, M., Kirschstein, M., Busch, C., et al. (1997) Oscillometric twenty-four-hour ambulatory blood pressure values in healthy children and adolescents: A multicenter trial including 1141 subjects. Journal of Pediatrics, 130(2), 178-84.

[4] Wühl, E., Witte, K., Soergel, M., Mehl, O. and Schaefer, F. (2002) German working group on pediatric hypertension Distribution of 24-h ambulatory blood pressure in children: Normalized reference values and role of body dimensions. Journal of Hypertension, 20(10), 1995-2007.

[5] Flynn, J.T. (2002) Differentiation between primary and secondary hypertension in children using ambulatory blood pressure monitoring. Pediatrics, 110(1), 89-93.

[6] Kavey, R.E., Kveselis, D.A., Atallah, N. and Smith, F.C. (2007) White coat hypertension in childhood: Evidence for end-organ effect. Journal of Pediatrics, 150(5), 491497.

[7] Jeck, N., Waldegger, P., Doroszewicz, J., Seyberth, H. and Waldegger, S.A. (2004) Common sequence variation of the CLCNKB gene strongly activates ClC-Kb chloride channel activity. Kidney International, 65(1), 190-197.

[8] Jeck, N., Waldegger, S., Lampert, A., et al. (2004) Activating mutation of the renal epithelial chloride channel $\mathrm{ClC}-\mathrm{Kb}$ predisposing to hypertension. Hypertension, 43(6), 1175-1181.

[9] Bender, J.U., Bonilla-Felix, M.A. and Portman, R.J. (2004) Epidemiology of hypertension. In: Avner, E.D. Harmon W.E. and Niaudet, P. Eds., Pediatric Nephrology, 5th Edition, Lippincot Williams and Wilkins, Philadelphia, 1125-1145.

[10] Croix, B. and Feig, D.I. (2006) Childhood hypertension is not a silent disease. Pediatric Nephrology, 21(4), 527532.

[11] Fava, C., Montagnana, M. and Almgren, P., et al. (2007) The functional variant of the CLC-KB channel T481S is not associated with blood pressure or hypertension in Swedes. Journal of Hypertension, 25(1), 111-116.

[12] Sile, S., Vanoye, C.G. and George, A.L.Jr. (2006) Molecular physiology of renal ClC chloride channels/ transporters. Current Opinion in Nephrology and Hypertension, 15(5), 511-516.

[13] Hansen, M.L., Gunn, P.W. and Kaelber, D.C. (2007) Underdiagnosis of hypertension in children and adolescents. Journal of the American Medical Association, 298(8), 874-879. 